\title{
Marine Gastropoda collected by the Steamer Albatross from the Philippines in 1908
}

\author{
Terrence M. Gosliner \\ Department of Invertebrate Zoology and Geology, California Academy of Sciences, \\ 875 Howard Street, San Francisco, CA 94103 USA. E-mail: tgosliner@calacademy.org
}

From 1887 until 1925, the United States Fish Commission's Steamer Albatross conducted pioneering marine explorations in the Pacific and Indian Oceans. Most of the results of these expeditions have been published in accounts of the expeditions and through numerous scientific papers dealing with particular marine taxa. The most ambitious expedition of the steamer's service was a two-and-a-half year expedition to the Philippine Islands, beginning in 1907, in the wake of the United States occupation of the Philippines following the Spanish American War. All of the collections of the gastropods illustrated here occurred during 1908.

Six civilian scientists participated in this expedition (http://www.nmnh.si.edu/vert/fishes/ albatross/exped.html), including the noted malacologist Paul Bartsch of the Smithsonian Institution's National Museum of Natural History. While the National Museum holds many collections from this expedition, there is only a fragmentary record of the opisthobranch and other slug-like mollusks from the expedition and it appears no other molluscan collections from the expedition are resident in the Smithsonian's collections, based on extensive searching of those collections. None of the preserved opisthobranch specimens are currently housed in the collections and are presumably lost. While I was conducting a postdoctoral fellowship in the Division of Mollusks at the Smithsonian Institution in 1982, Diane Tyler, then a curatorial assistant in the Division, brought to my attention a series of original paintings, kept in the Mollusk Division, of opisthobranchs and other mollusks collected in 1908 as part of the Albatross Expedition to the Philippines. These paintings were undertaken by the expedition artist Kumataro Ito. While many of Ito's fish paintings have been published (Springer 1999) and are accessible via the internet (http:// www.nmnh.si.edu/vert/fishes/albatross/ illusito.html), these molluscan illustrations have never been published. In the absence of preserved specimens, the mollusc illustrations constitute the only record of gastropod molluscs from the expedition that are known to exist.

The scientific accuracy of these paintings is generally striking and the majority of the fifty-three illustrations can be identified to species (Table 1). Several of these taxa have been described only recently and at least two of the identifiable taxa remain undescribed. The significance of these paintings has only been briefly documented (Gosliner and Tyler 1990) and the only illustration published was presented by Elwood et al. (2000) in their original description of Aldisa albatrossae.

Included in this paper are many of Ito's paintings of species that are readily identifiable together with colour photographs of living animals of these species. Also included are some of the remaining paintings of Ito's that could not be readily identified. Only thirteen of the species depicted cannot be linked with described, or known but undescribed, species. Of these only two cannot be identified or tentatively placed in known genera. The vast majority of taxa represented are opisthobranch gastropods, but also included is one species of vetigastropod, three species of caenogastropod and one pulmonate. Members of these vetigastropod and caenogastropod taxa have internal shells and are often included in collections of opisthobranchs, as are the unshelled pulmonates of the Onchidiidae. Of the opisthobranch gastropods one is a species of cephalaspidean, three are anaspideans, three are notaspideans and the remainder are nudibranchs. The tentative identification of each taxon is included in Table 1.

In order to demonstrate the diagnostic nature of the illustrations a series of them are reproduced here together with photographs of living animals of the same species from different localities throughout the tropical Indo-Pacific (Figures. 1-6). Figures $6 \mathrm{~K}$ and $6 \mathrm{~L}$ depict two species that cannot be readily identified with any described or known undescribed species. The first one appears to be an undescribed species of Tritonia while the second appears to be a species of Dendrodoris. It is interesting to note that the illustration of the Dendrodoris includes a drawing of the egg mass of this species. From the presence of relatively few, large eggs, it appears that this species has direct rather than planktonic development. Direct development appears to be very uncommon in 
Table 1 List of marine gastropods illustrated by Ito from the Albatross expedition to the Philippines.

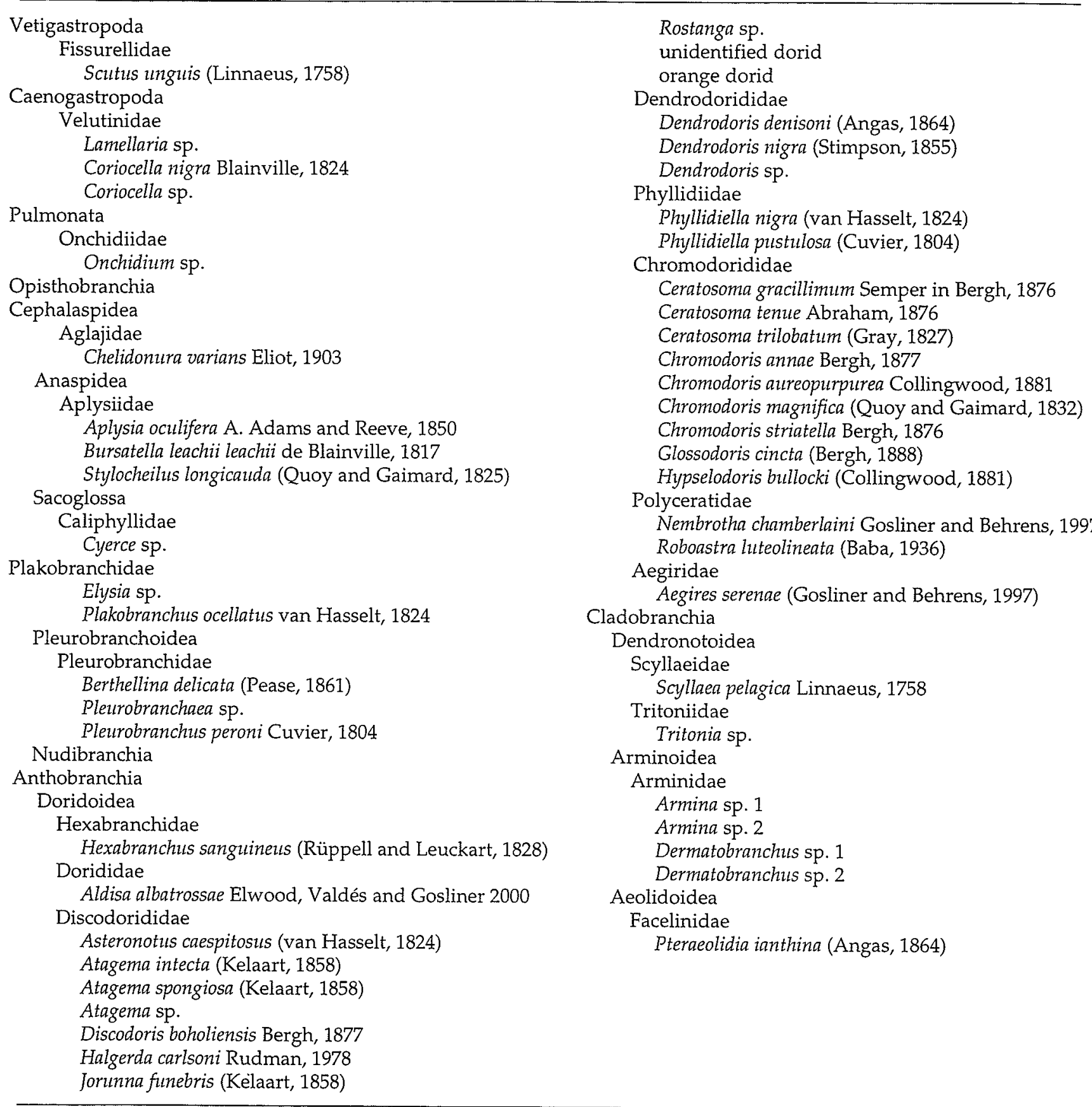

tropical Indo-Pacific taxa (personal observation). Inclusion of life-history data increases the value of these important illustrations that document a small sample of the marine opisthobranch biodiversity of the Philippine Islands. While many of the taxa included here are relatively common in the Philippine Islands, others have not been collected there since these illustrations were made.

Remarks for each species indicate the basis for the identifications that have been determined within the present study.

Scutus unguis (Linnaeus, 1758). (Figures 1A, B). This vetigastropod is characterized by having a uniformly black pigmented mantle with a frilled margin. The outline of the internal shell can clearly be seen in Ito's illustration.

Lamellaria sp. This species is depicted in two paintings, one of a dorsal view and the second of the ventral aspect. The pink mantle with a longitudinal band is distinctive. The ventral view with a broad foot and deeply divided elongate oral tentacles clearly indicate that this is a species of Lamellaria. The systematics of the Indo-Pacific members of this taxon remain poorly known and the degree of variability and species limits require additional detailed study.

Coriocella nigra Blainville, 1824. (Figures 1C, D). The uniformly velvety black color of this species with a 

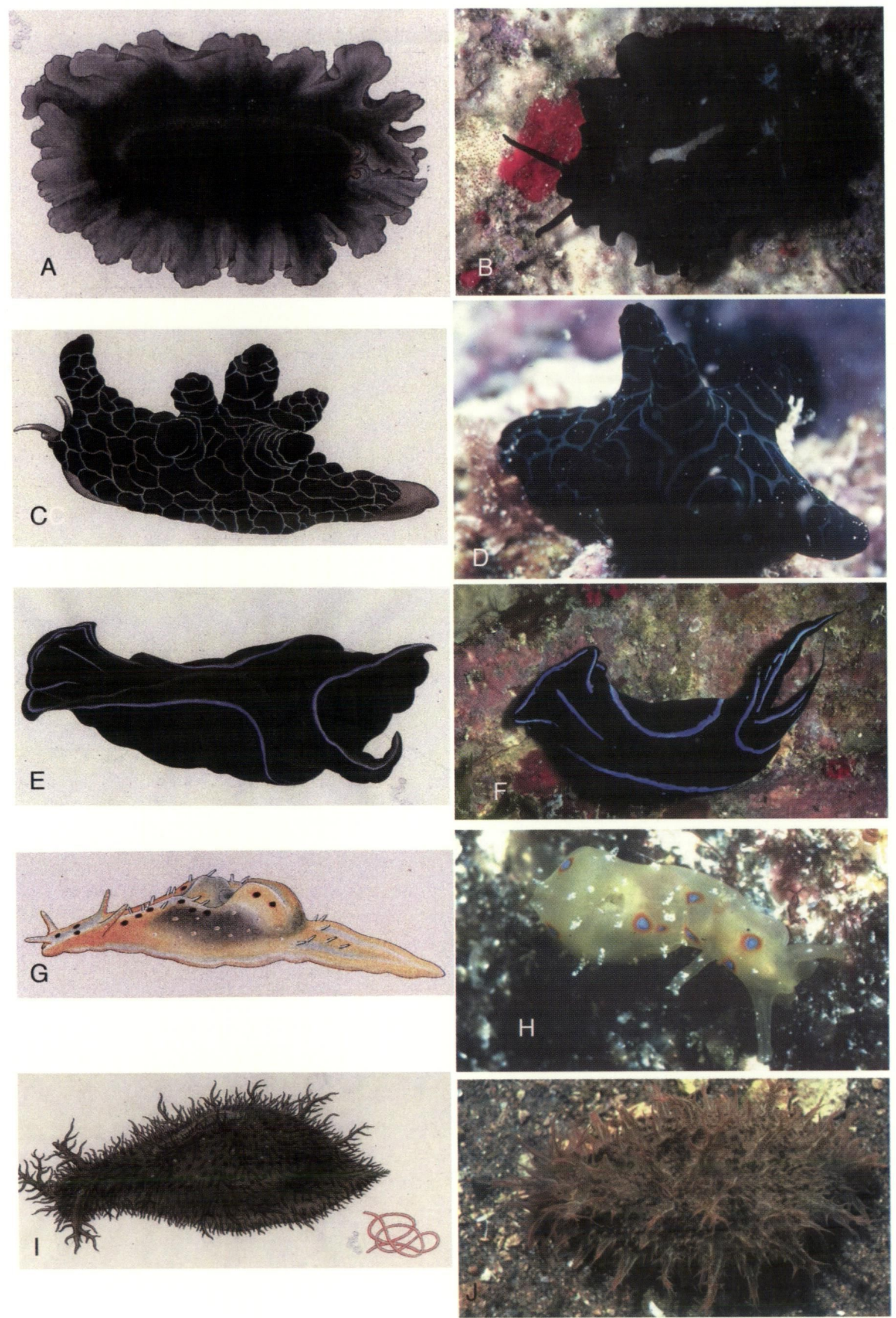

Figure 1 A., B. Scutus unguis (Linnaeus, 1758), photo: Bagabag Island, Madang, Papua New Guinea. C., D. Coriocella nigra Blainville, 1824, photo: Jerry Allen, Batangas, Luzon Philippines. E., F. Chelidonura varians Eliot, 1903, photo: Olango, Cebu, Philippines. G.,H. Stylocheilus longicauda (Quoy and Gaimard, 1825), photo: Madang, Papua New Guinea. I.J. Bursatella leachii leachii de Blainville, 1817, photo: Salt Rock, Natal, South Africa. 
tuberculate mantle is distinctive. The four dorsal lobes of the mantle are also characteristic of this species.

Coriocella sp. The lighter mantle color and shorter mantle lobes differ from the above species. The degree of variation present in species of Coriocella requires further investigation.

Onchidium sp. The tuberculate body with elongate tentacular eye-stalks and bilobed velum indicate that this figure illustrates a species of Onchidiidae, most likely a species of Onchidium.

Chelidonura varians Eliot, 1903. (Figures 1E, F). The black body color with blue lines on the parapdodia and dorsum and elongate posterior mantle lobes readily identify this species as Chelidonura varians. Stylocheilus longicauda (Quoy and Gaimard, 1825). (Figures 1G, H). The pale yellowish body with short papillae and elongate foot indicate that this is likely Stylocheilus longicauda. Typically living specimens have prominent blue ocelli that are not readily evident in Ito's illustration.

Bursatella leachii leachii de Blainville, 1817. (Figures 1I, J). This sea hare is readily distinguished by its mantle ocellae and dense covering of ramified papillae.

Aplysia oculifera A. Adams and Reeve, 1850. (Figures 2A, B). This is one of the few Indo-Pacific species of Aplysia that is capable of swimming. The widely open mantle lobes in Ito's left illustration indicate that the animal is in swimming posture. The black ocellae of the living animal are not evident in Ito's illustration.

Elysia sp. (Figures 2C, D). The animal depicted in Ito's illustration represents an undescribed species of Elysia that has been found sporadically in the Philippines and Papua New Guinea (present study). This species is similar to the common circumtropical species Elysia ornata (Swainson, 1840) and like that species has white and black parapodial margins. Elysia ornata has an additional orange marginal line that is absent in E. sp. Elysia sp. also has a $y$-shaped opaque white marking on the head that is absent in E. ornata.

Cyerce sp. (Figures 2E, F). This represents an undescribed species of Cyerce. The yellow to orange cerata tips with stippled circles of brown pigment are characteristic of this species.

Plakobranchus ocellatus van Hasselt, 1824. (Figures $2 \mathrm{G}, \mathrm{H})$. The widely separated rhinophores and ocellae on the mantle are characteristic of Plakobranchus ocellatus. A second specimen is also represented in Ito's paintings, but this individual has less prominent ocellae.

Berthellina delicata (Pease, 1861). (Figures 2I, J). The uniformly smooth orange mantle with darker viscera visible through the mantle is characteristic of species of Berthellina. Berthellina delicata is the common member of the genus found in the western Pacific (Cervera and Gosliner, in preparation).
There are no external characteristics that distinguish species of Berthellina. As such, the identification made here is based exclusively on the fact that all specimens of Berthellina from the Philippines examined to date are $B$. delicata, based on their genitalia.

Pleurobranchus peroni Cuvier, 1804. (Figures 2K, $\mathrm{L})$. The finely reticulate orange mantle with scattered opaque white spots is characteristic of Pleurobranchus peroni.

Pleurobranchaea sp. The illustration of this species with an extruded buccal mass, a pallid color and a wrinkled mantle indicate the specimen was dead or moribund at the time it was illustrated. The widely separated rhinophores and lateral gill clearly indicate that it is a species of Pleurobranchaea. The most common member of this genus in Philippine waters is P. brockii Bergh, 1897 (present study) and this is most likely the species depicted by Ito.

Hexabranchus sanguineus (Rüppell and Leuckart, 1828). (Figures 3A, B). The swimming posture of this large orange dorid with fimbriate oral tentacles indicate that it can only be the common Spanish Dancer, Hexabranchus sanguineus.

Aldisa albatrossae Elwood, Valdés and Gosliner 2000. (Figures 3C, D). Ito's drawing of this species has been previously identified as Aldisa albatrossae (Elwood, Valdés and Gosliner 2000).

Asteronotus cespitosus (van Hasselt, 1824). (Figures $3 \mathrm{E}, \mathrm{F})$. The brownish body with mid-dorsal ridge, strong, irregular tubercles and concentric rings of marginal tubercles readily identify this illustration as Asteronotus cespitosus.

Atagema intecta (Kelaart, 1858). (Figures 3G, H). The brown, tuberculate body with mid-dorsal, longitudinal opaque white stripe is characteristic of Atagema intecta.

Atagema spongiosa (Kelaart, 1858). (Figures 3I, J). The finely granular surface of the body with distinct holes resembling the oscula of sponges indicates that this species is most likely Atagema spongiosa, although the possibility that it represents an undescribed species cannot be completely eliminated.

Atagema sp. (Figures 3K, L). This species with a reticulate brownish to pink notum and a smooth longitudinal band probably represents the undescribed species of Atagema shown in the adjacent photo.

Discodoris boholiensis Bergh, 1877. (Figures 4A, B). The brownish color with branching, lighter, radiating lines near the mantle margins suggest that Ito's drawing represents Discodoris boholiensis.

Halgerda carlsoni Rudman, 1978. (Figures 4C, D). The white body with ridges punctuated by large orange dots and smaller orange specks is characteristic of Halgerda carlsoni. The gill and rhinophores are also ornamented with dark brown to black specks. 

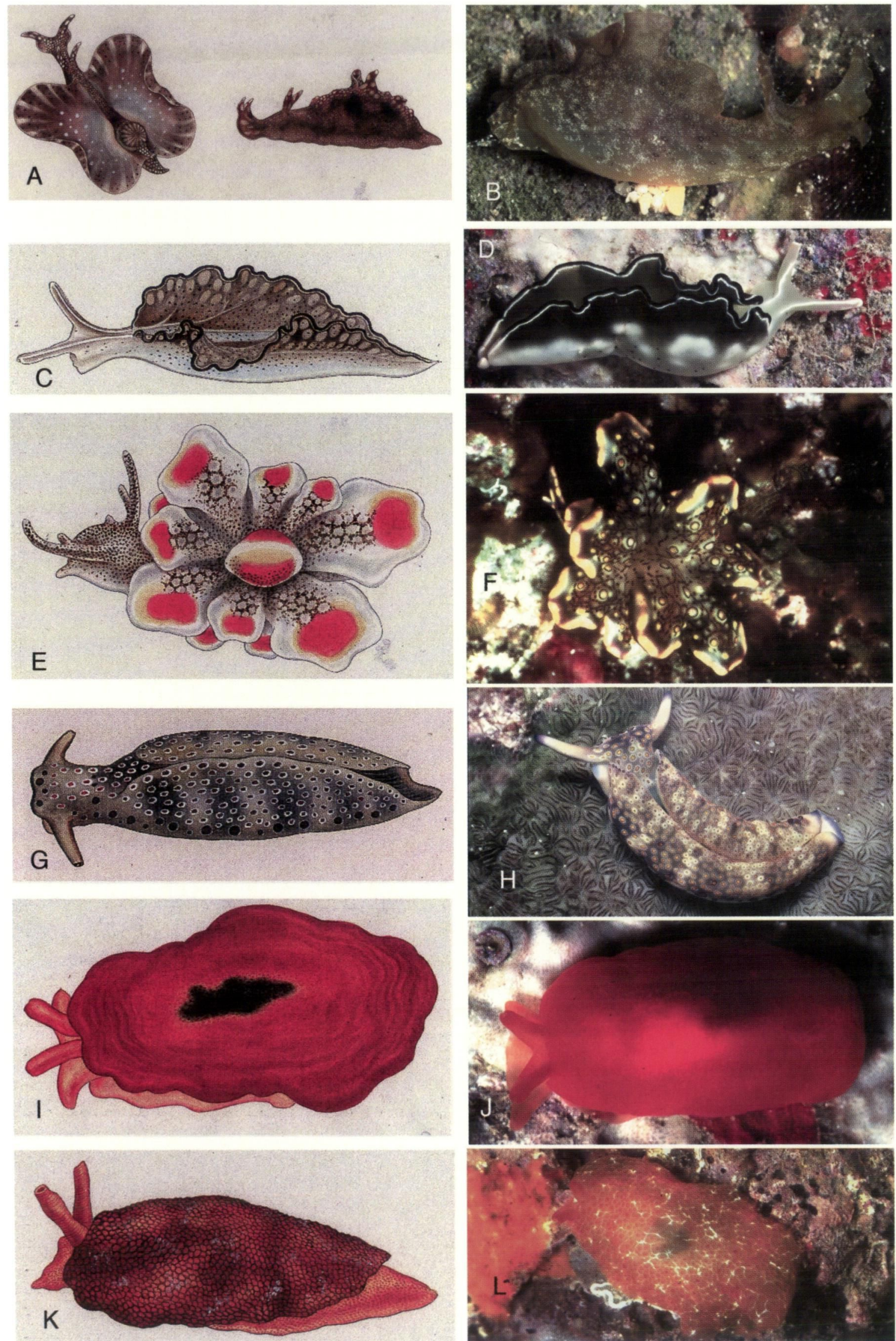

Figure 2 A., B. Aplysia oculifera A. Adams and Reeve, 1850, photo: Midway Atoll. C., D. Elysia sp., photo: Madang, Papua New Guinea. E., F. Cyerce sp., photo: Madang, Papua New Guinea. G., H. Plakobranchus ocellatus van Hasselt, 1824, photo: Madang, Papua New Guinea. I., J. Berthellina delicata (Pease, 1861), photo: Madang, Papua New Guinea. K., L. Pleurobranchus peroni Cuvier, 1804, photo: Tulamben, Bali, Indonesia. 

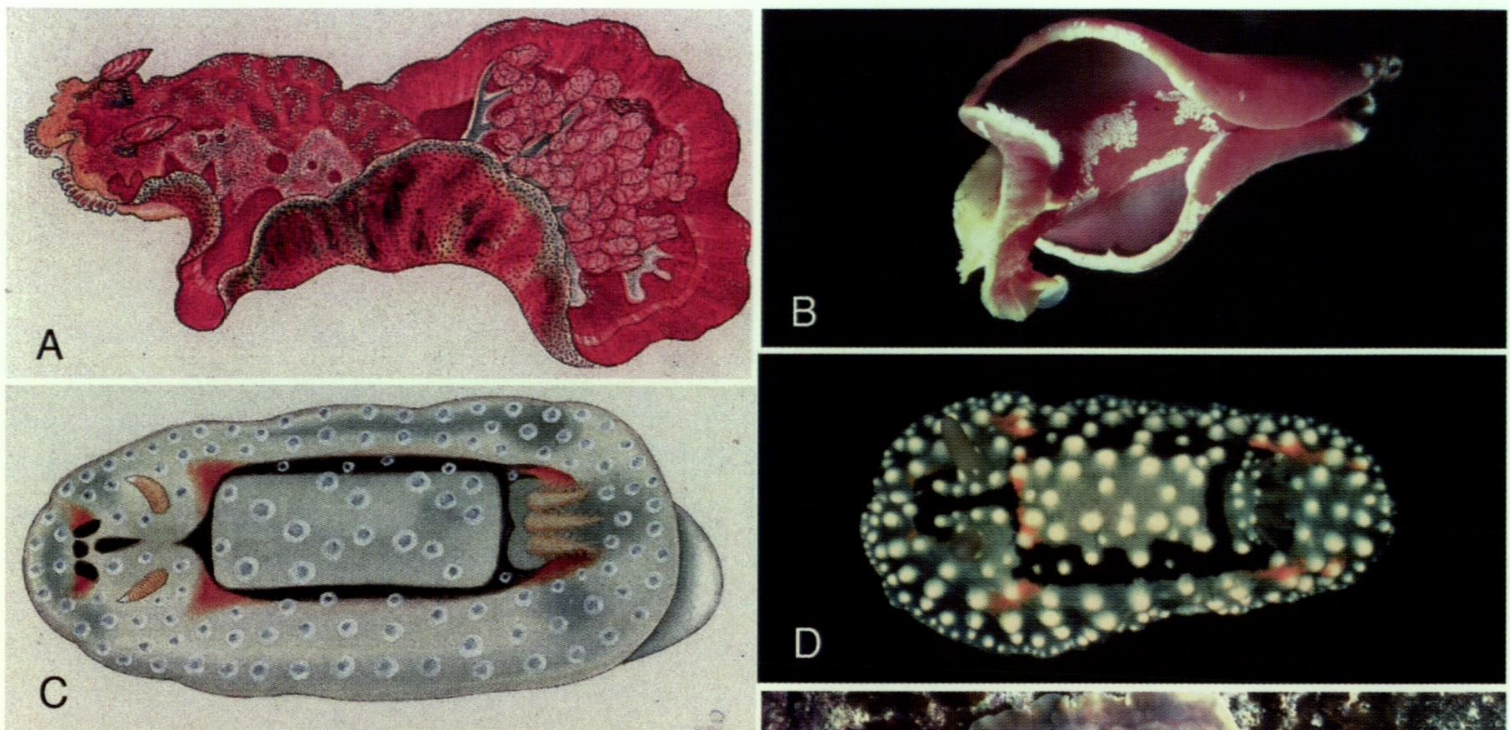

D
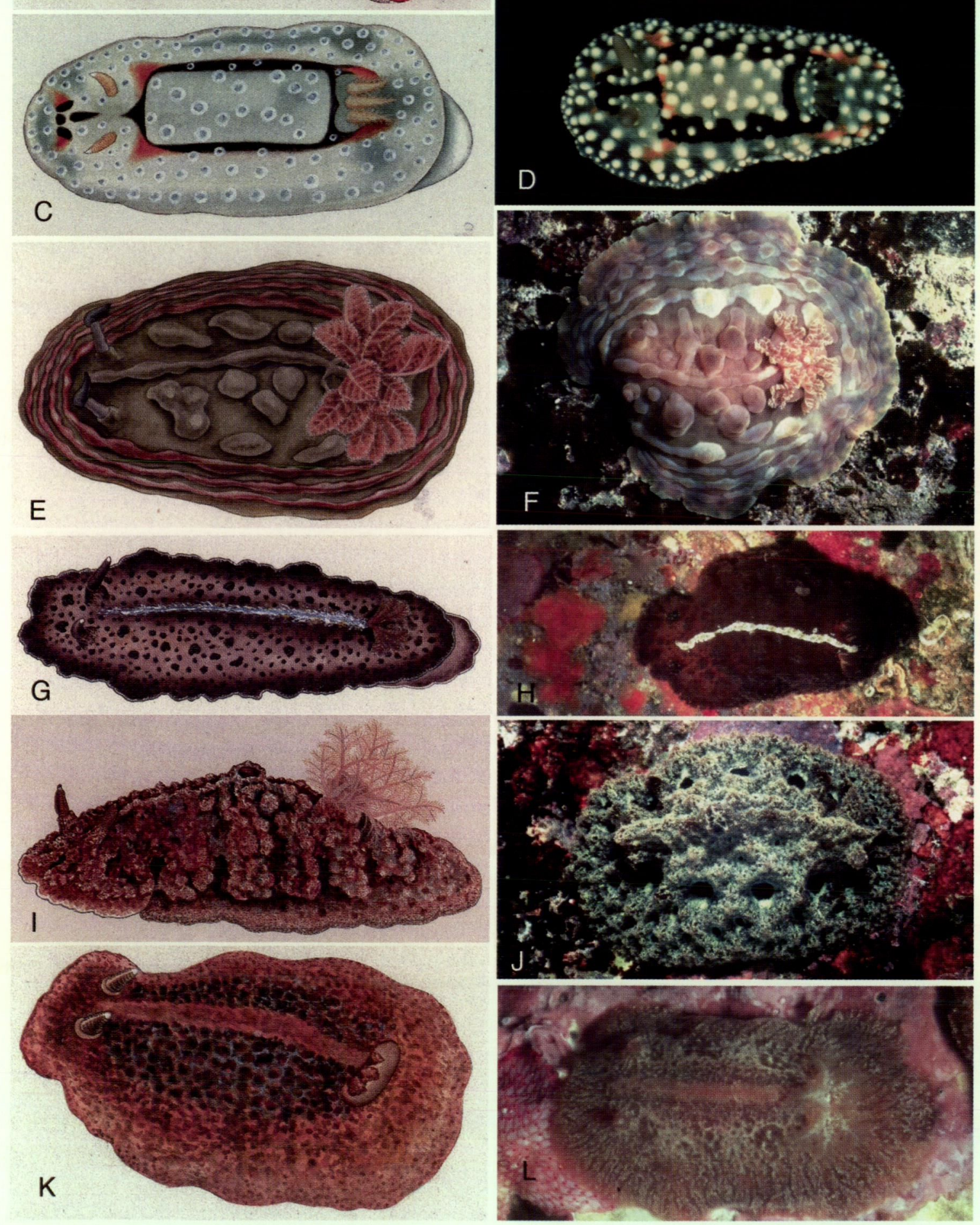

Figure 3 A., B. Hexabranchus sanguineus (Rüppell and Leuckart, 1828), photo: Koloa, Kauai, Hawaii. C., D. Aldisa albatrossae Elwood, Valdés and Gosliner 2000, photo: Robert Bolland, Okinawa, Ryukuyu Islands, Japan. E., F. Asteronotus cespitosus (van Hasselt, 1824), photo: Madang, Papua New Guinea. G., H. Atagema intecta (Kelaart, 1858), photo: Batangas, Luzon, Philippines. I., J. Atagema spongiosa (Kelaart, 1858), photo: Madang, Papua New Guinea. K., L. Atagema sp., photo: Batangas, Luzon Philippines. 

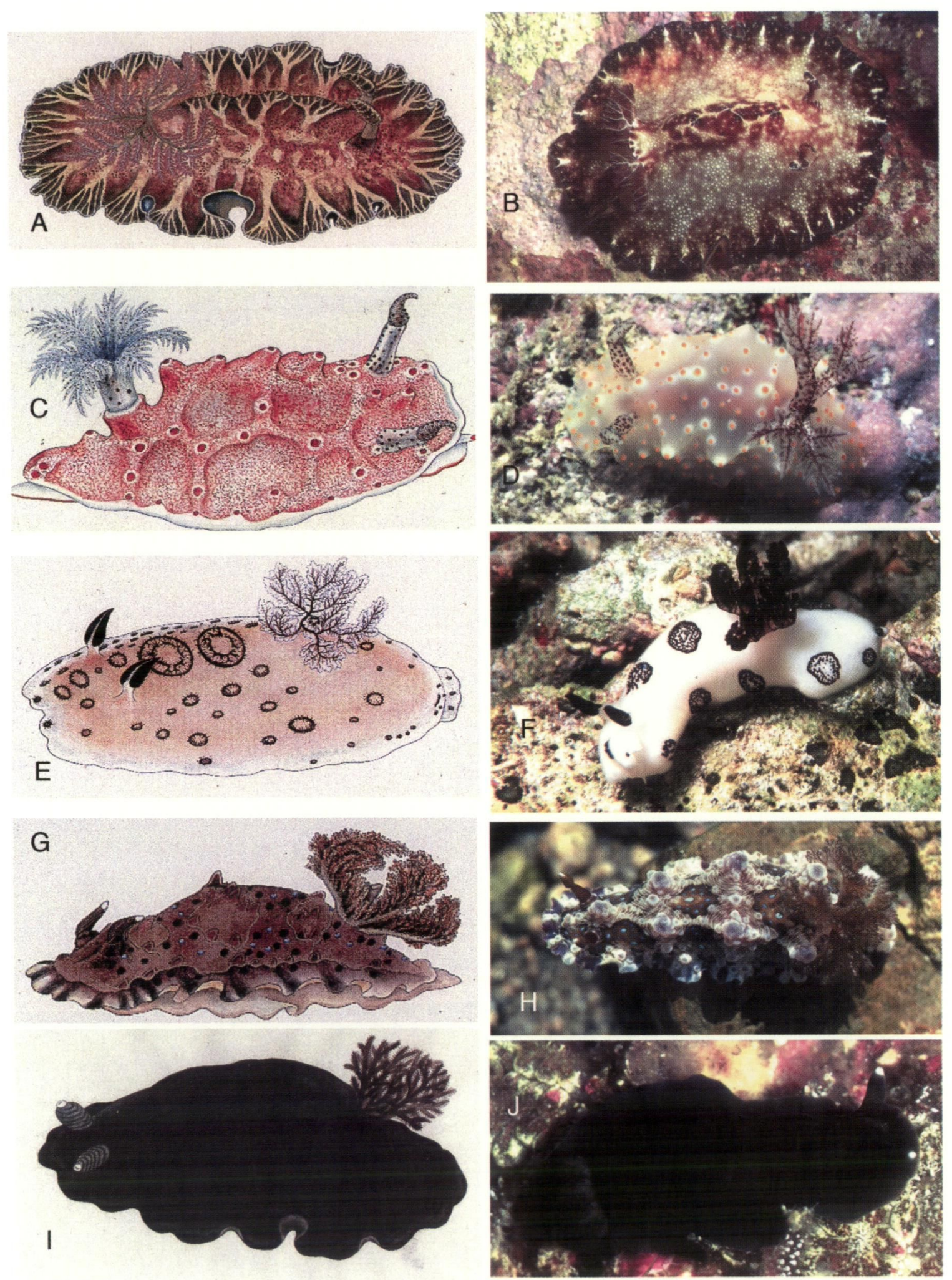

Figure 4 A., B. Discodoris boholiensis Bergh, 1877, photo: Batangas, Luzon Philippines. C., D. Halgerda carlsoni Rudman, 1978, photo: Madang, Papua New Guinea. E., F. Jorunna funebris (Kelaart, 1858), photo: Louisiade Archipelago, Papua New Guinea. G., H. Dendrodoris denisoni (Angas, 1864), photo: Salt Rock, Natal, South Africa. I., J. Dendrodoris nigra (Stimpson, 1855), photo: Madang, Papua New Guinea. 

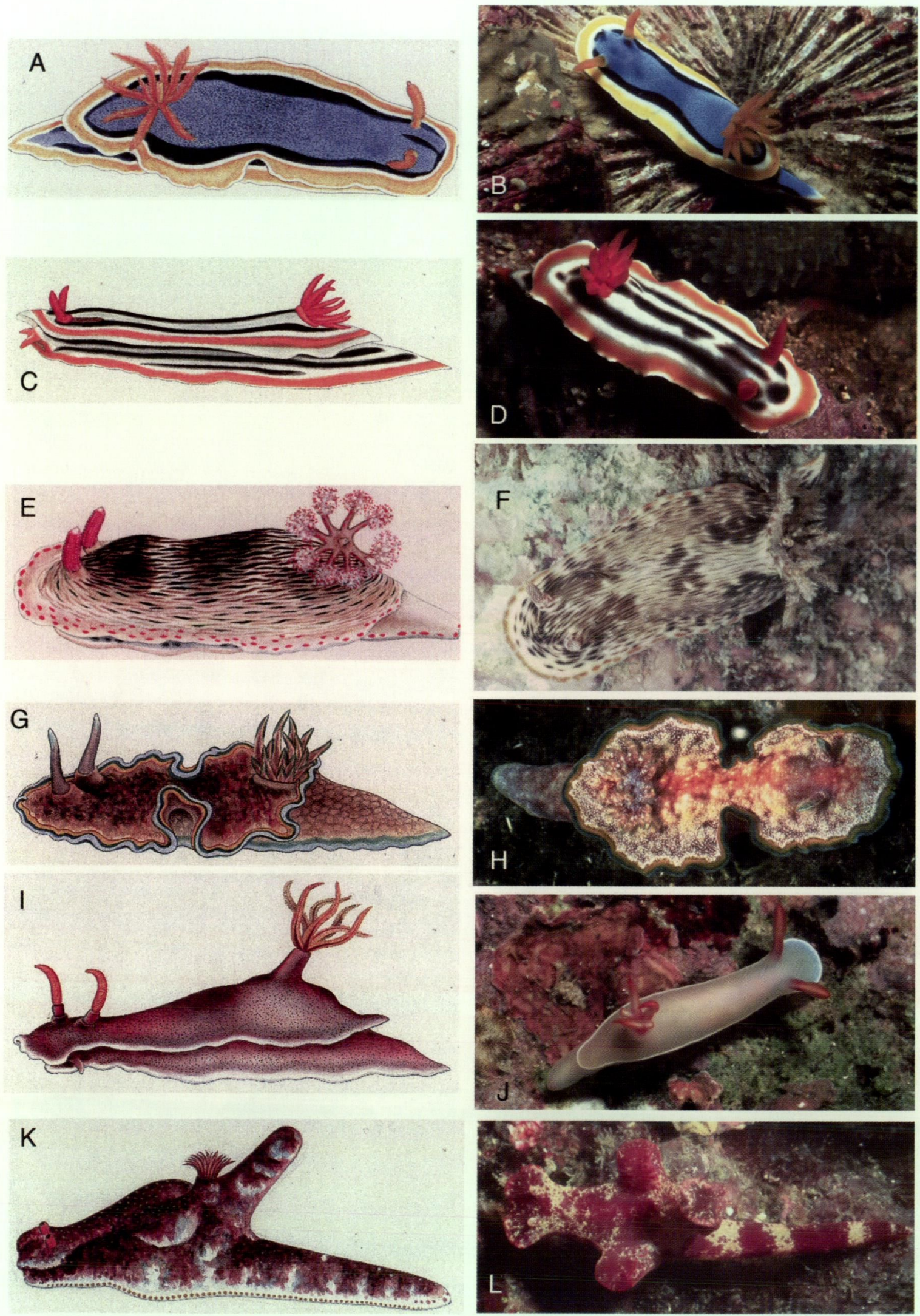

Figure 5 A., B. Chromodoris annae Bergh, 1877, photo: Batangas, Luzon, Philippines. C., D. Chromodoris magnifica (Quoy and Gaimard, 1832), photo: Batangas, Luzon, Philippines. E., F. Chromodoris striatella Bergh, 1876, photo: Pauline Fiene, Adonara, Indonesia. G., H. Glossodoris cincta (Bergh, 1888), photo: Tulamben, Bali, Indonesia. I., J. Hypselodoris bullocki (Collingwood, 1881), photo: Puerto Galera, Mindoro, Philippines. K., L. Ceratosoma gracillimum Semper in Bergh, 1876, photo: Batangas, Luzon, Philippines. 
lormmna funebris (Kelaart, 1858). (Figures 4E, F) The white body with black rings, black gill and rhinophores is characteristic of Jormma funclris.

Rostanga sp. The uniformly red-orange granular body indicates that this dorid is most likely a species of Rostanga.

unidentified dorid. This dorid with a granular texture, unipinnate gill branches and anastamosing reddish lines cannot readily be placed in any specific group of cryptobranch dorids.

Dendrodoris denisoni (Angas, 1864). (Figures 4G, H). The brownish body with bright blue spots, large gill and rhinophores strongly suggest that Ito's drawing represents Dendrodoris denisoni.

Dendrodoris nigra (Stimpson, 1855). (Figures 4I, J). Ito's drawing of an animal with a black notum and a lighter marginal band, sparsely pinnate gill and white apices of the rhinophores strongly suggests that this is Dendrodoris nigra.

Dendrodoris sp. (Figure 6L). It appears that this mottled dorid with large rhinophores represents a species of Dendrodoris. The egg mass (drawn by Ito and shown for this species in Figure 6L) indicates an egg mass with few, large eggs suggesting that this species has direct development.

orange dorid. This reddish orange dorid with a pustulose notum and no readily evident dorsal gill may be a species of Phyllidiidae.

Phyllidiella nigra (van Hasselt, 1824). The black body with large rounded lighter tubercles suggests that this species is likely Phylliticlla nigra.

Phyllidiella pustulosa (Cuvier, 1804). The low irregular, pinkish tubercles of this black animal suggest that it is likely Phyllidiella pustulosa.

Chromodoris annae Bergh, 1877. (Figures 5A, B). The distinctive pattern of a blue body without longitudinal black bands with orange margin is characteristic of Chromodoris annae.

Chromodoris magnifica (Quoy and Gaimard, 1832). (Figures 5C, D). The white body with black longitundinal lines, orange margin, orange gill and rhinophores is distinctive for Chromodoris magnifica. Chromodoris striatella Bergh, 1876. (Figures 5E, F). A white body with a series of brown lines or varying intensity is a distinguishing feature of Chromodoris striatella, as are the orange marginal spots and rhinophores with opaque white spots.

Chromodoris aureopurpurea Collingwood, 1881. This species with a white body and brownish notal spots and a blue margin is similar to that of Chromodoris aureopunctata and C. rufomaculata Pease, 1871. The egg mass is also illustrated.

Glossodoris cincta (Bergh, 1888). (Figures. 5G, H). The brownish body with blue and orange marginal bands and deeply indented central portions of the mantle are characteristic of Glossodoris cincta.

Hypselodoris bullocki (Collingwood, 1881). (Figures. 5I, J). Ito's drawing of Hypselodoris bullocki is very characteristic with the elevated gill- base, orange rhinophore and gill, opaque white marginal band and reddish purple body color. Ceratosoma gracillimum Semper in Bergh, 1876. (Figures 5K, L). The relatively uniform reddish body color with numerous spots of mottling and color indicate that Ito's illustration of this species is most likely Ceratosoma gracillimmm.

Ceratosoma tenuc Abraham, 1876. The reddish mottled body with relatively little expansion of the mantle and a purple marginal line suggest that this species is most likely Ceratosonta tenul?

Ceratosoma trilobatum (Gray, 1827). The reddish body, wide mantle lobes suggest that this species is most likely Ceratosoma trilobatum.

Aegires serenae (Gosliner and Behrens, 1997). (Figures 6A, B). The distinctive greenish color, large branchial lobes and smooth rhinophores are characteristic for Acgires serenae.

Nembrotha chamberlaini Gosliner and Behrens, 1997. (Figures 6C, D). The white body color with brownish pigment on the center of the notum and a red gill are characteristic for the common Philippine species, Nembrotha chamberlaini.

?Roboastra luteolineata (Baba, 1936). This illustration of Ito's suggests that the black animal with numerous longitudinal lines of yellow may be Roboastra luteolineata. The large oral tentacles that are characteristic of this species are not evident in Ito's drawing, suggesting it may also represent a species of Tambia or that this characteristic was omitted from the drawing

Scyllaea pelagia Linnaeus, 1758. (Figures 6E, F). This species is quite distinctive with its four large mantle lobes and expanded rhinophore sheaths. There is little doubt that this is Scyllaen pelagica.

Tritonin sp. (Figure 6K). This white species with darker pigment on the head, appears to be a species of Tritonia, but cannot be identified with any known species.

Armina sp. 1. (Figures 6G, H). This species with a red body and numerous opaque white longitudinal lines appears to be undescribed. The specimen depicted by Ito closely matches a specimen collected from Anilao, Batangas, Philippines (Figures 6H).

Armina sp. 2. Ito illustrated a second species of Armina with uniform orange pigment and low longitudinal ridges. It cannot be readily identified with any known species.

Dermatobranchus sp. 1. Ito illustrated a dark gray species of Dermatobranchus with lighter longitudinal lines. This species cannot be readily identified with any known species.

Dermatobranchus sp. 2. A second species of Dermatobranchus was illustrated by Ito. It is also gray in color with lighter longitudinal lines. It differs from the previous species in having more prominent rhinophores that are ornamented with yellow pigment. The same yellow pigment is found 

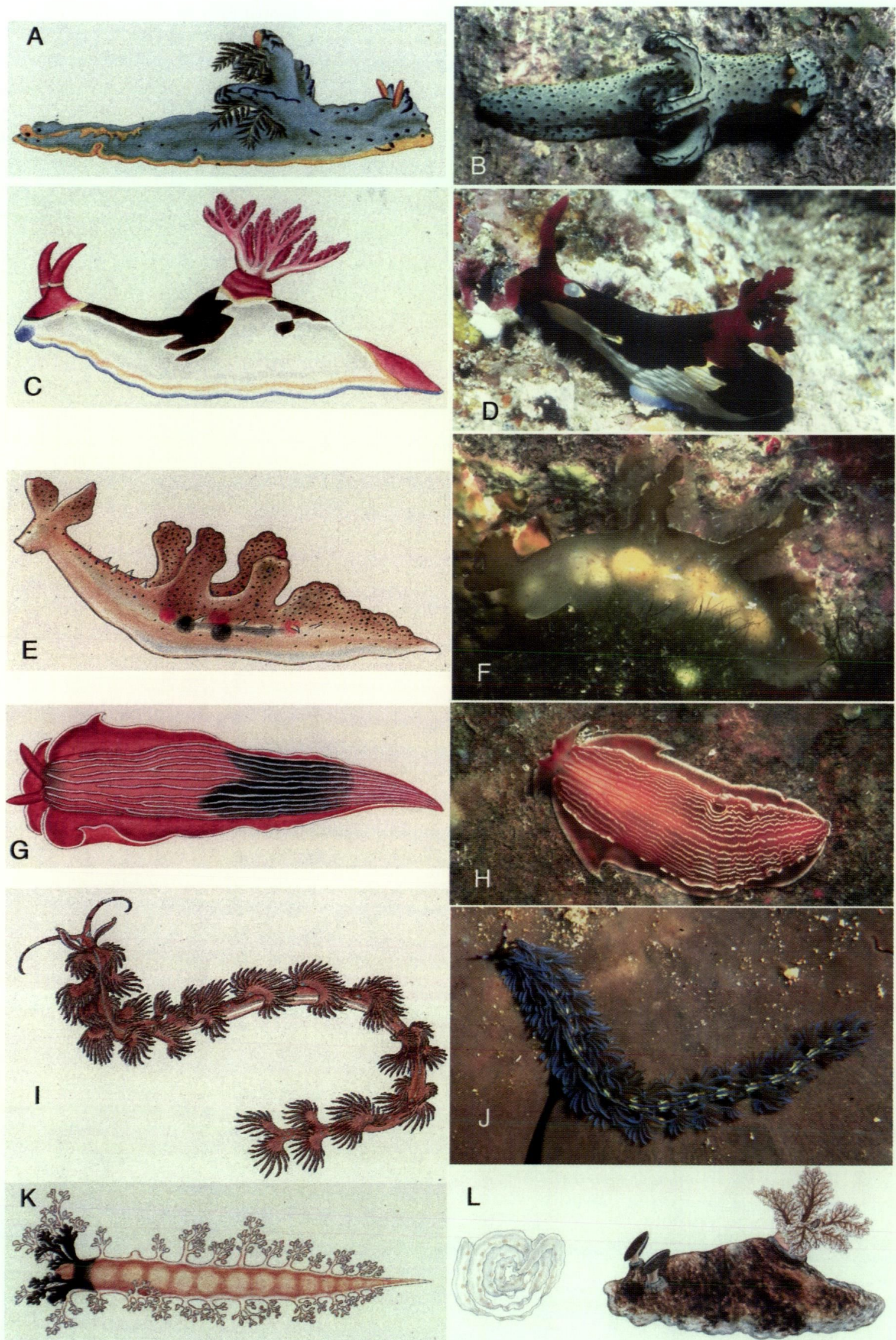

Figure 6 A., B. Aegires serenae (Gosliner and Behrens, 1997), photo: Madang, Papua New Guinea. C., D. Nembrotha chamberlaini Gosliner and Behrens, 1997, photo: Batangas, Luzon Philippines. E., F. Scyllaea pelagica Linnaeus, 1758, photo: Madang, Papua New Guinea. G., H. Armina sp., photo: Batangas, Luzon, Philippines. I., J., Pteraeolidia ianthina (Angas, 1864), photo: Batangas, Luzon, Philippines. K. Tritonia sp. L. Dendrodoris sp. 
along the margin of the foot. This species cannot be readily identified with any known species.

Pteraeolidia ianthina (Angas, 1864). (Figures 6I, J) The elongate body shape, elevated ceratal clusters and elongate oral tentacles make Ito's illustration immediately identifiable with Pteraeolidia ianthina.

While tentative identifications are made here for all of the material illustrated by Ito during the Albatross Expedition, only 35 of Ito's 53 illustrations are included in the plates presented here. All of the images, including those not included in this paper will be posted on the Nudibranch PEET webpage: http://www.calacademy.org/research/izg/ nudibranchs/.

\section{ACKNOWLEDGEMENTS}

I wish to thank Diane Tyler for first bringing the existence of Ito's paintings of mollusks to my attention and for her enthusiastic interest in the historical importance of these surviving documents of the Albatross expedition. I also wish to thank many individuals who have contributed to the knowledge of Philippine opisthobranchs and assisted in our various field expeditions. I also wish to thank Bob Bolland who has advanced our knowledge of the opisthobranch fauna from the nearby Ryukuyu Islands of Japan. This work was supported by a National Science Foundation PEET grant DEB 0329054 Phylogenetic systematics of dorid nudibranchs to the author and Ángel Valdés.

\section{REFERENCES}

Elwood, H. A. Valdés and T. Gosliner 2000. Two new species of Aldisa Bergh, 1878 (Mollusca, Nudibranchia) from the tropical Indo-Pacific. Proceedings of the California Academy of Sciences 52: 171181.

Gosliner, T. and D. Tyler. 1990. Marine Gastropods collected by the Steamer Albatross in 1908. Western Society of Malacologists Annual Report 22: 15.

Springer, V. 1999. Kumataro Ito, Japanese Artist on Board the U.S. Bureau of Fisheries Steamer Albatross During the Philippine Expedition, 1907-1910. Marine Fisheries Review 61: 42-57. 